\title{
The Dynamic Theory of Time and Time Travel to the Past
}

\author{
Ned Markosian \\ University of Massachusetts Amherst

\begin{abstract}
I argue that time travel to the past is impossible, given a certain metaphysical theory, namely, The Dynamic Theory of Time. I first spell out my particular way of capturing the difference between The Dynamic Theory of Time and its rival, The Static Theory of Time. Next I offer four different arguments for the conclusion that The Dynamic Theory is inconsistent with the possibility of time travel to the past. Then I argue that, even if I am wrong about this, it will still be true that The Dynamic Theory entails that you should not want to travel back to the past. Finally, I conclude by considering a puzzle that arises for those who believe that time travel to the past is metaphysically impossible: What exactly are we thinking about when we seem to be thinking about traveling back in time? For it certainly does not feel like we are thinking about something that is metaphysically impossible.
\end{abstract}

\section{Keywords}

Time travel, Dynamic Theory of Time, Static Theory of Time, backward causation, presentism.

\section{Introduction}

Most people will tell you that the inexorable passage of time is a real thing, and (for better or worse) one of the more salient aspects of reality. ${ }^{1}$ For most people endorse what is sometimes called The Dynamic Theory of Time, according to which time really passes, and there are fundamental differences between the past, the present, and the future. But most people also love a good time travel story,

\footnotetext{
${ }^{1}$ By 'most people' I do not mean most philosophers but, rather, most people in general.
} 
and would probably jump at the chance to travel back in time (either going back and merely blending in, so that nothing changes, or else going back and changing the past), if only they could.

All of this is a problem, I will argue, because The Dynamic Theory of Time entails that time travel to the past is not merely difficult, or prohibitively expensive, but downright metaphysically impossible. If The Dynamic Theory is true, as most people believe, then it is not possible to travel back in time. Not only that but, as I will further argue, even if I happen to be wrong about The Dynamic Theory entailing the metaphysical impossibility of time travel to the past, it will still be true that The Dynamic Theory entails that we should not want to travel back to the past. So most people want to do a thing that they should not want to do (given what they believe about time), and that is in fact not even possible (again given what they believe about time).

Or so I will argue in this paper. Then I will address a further puzzle that arises from the thesis that time travel to the past is metaphysically impossible: Many of our favorite stories involve time travel to the past, but do not have the distinctive feel of a story based on a metaphysically impossible premise. This raises a question concerning what we are thinking about when we consider time travel stories. In the last section of the paper I will try to resolve this puzzle in a way that is consistent with my thesis that time travel to the past is metaphysically impossible.

But before I get to all of that, I want to start by offering a new way of capturing the distinction between The Dynamic Theory of Time and its rival, The Static Theory of Time.

\section{Two theories about the nature of time}

The guiding thought behind The Static Theory of Time is that time is similar to space. ${ }^{2}$ Some people think this follows from The

\footnotetext{
${ }^{2}$ The degree to which time is thought to be similar to the dimensions of space will vary from one Static Theorist to another. For example, some Static Theorists may want to take the asymmetry in what is allowed along time-like dimensions by special relativity (or some other physical theory) to be an intrinsic feature of time itself, rather than merely a contingent fact about the spread of physical phenomena in the actual universe. And such people will want to say that time is different in at least some important respects from the other dimensions of the spacetime
} 
Special Theory of Relativity, but in my view that is a mistake. The idea that time is like space is certainly an interesting - and even compelling - way to think about time, but it is not forced upon us by The Special Theory of Relativity, or indeed by any other empirical theory. ${ }^{3}$

Here is some terminology that will be useful in stating both The Static Theory and The Dynamic Theory. ${ }^{4}$

A-properties: putative temporal properties such as being present, being past, being future, being four days future, etc.

B-relations: temporal relations such as simultaneous with, earlier than, later than, four days later than, etc.

And here are six ways in which time is supposed to be like space, on The Static Theory of Time. ${ }^{5}$ (It is worth emphasizing that the different components I am building into The Static Theory need not all be combined in this way. There are various "mix and match" combinations that have been endorsed in print. But the combination presented here is probably the most popular in the literature, and arguably the most interesting. It is also worth emphasizing that, since all of the arguments below are concerned with what is entailed by The Dynamic Theory of Time, rather than The Static Theory, nothing in what follows turns on the choice of a specific version of The Static Theory.)

manifold. But all Static Theorists will agree that time is in some significant ways similar to the dimensions of space.

${ }^{3}$ This point has been made before. See for example Emery 2019, Hinchliff 2000, Miller 2004, Markosian 2004: Section 3.9, and Zimmerman 2008: 218-21.

${ }^{4}$ The terms 'A-property' and 'B-relation' are first used together in Markosian 1993, but they derive from McTaggart's talk of an A-series and a B-series. See McTaggart 1908.

${ }^{5}$ Some or all of the following components of The Static Theory can be found in Williams 1951, Price 1977, Smart 1966, Lewis 1976, Sider 2001, Hawley 2001, and Moss 2012. (As well as many other places.) Much more could be said about each of the components of the theory. But then this paper would be a book. 
The Static Theory of Time

1. The universe is spread out in four dimensions (each one orthogonal to each other one), which together make up a unified, four-dimensional manifold (appropriately called spacetime) in which physical objects are located and possibly extended.

2. Any physical object that persists through time does so in virtue of having a temporal part at each moment at which it is present.

3. There are no genuine and irreducible A-properties; all talk that appears to be about A-properties can be correctly analyzed in terms of B-relations.

4. The temporal facts about the world include facts about B-relations, but they do not include any facts about A-properties.

5. We do not need to take tense seriously. Propositions have truth values simpliciter rather than at times, and so cannot change their truth values over time. Also, we can in principle eliminate verbal tenses like is, was, and will be from an ideal language.

6. The correct ontology does not change over time, and it always includes objects from every region of spacetime.

Static Theorists admit that time seems special to us, and that in fact time appears to have a dynamic aspect that makes it different from space. But they insist that this is just a subjective feature of consciousness - of how we experience the world - and not an objective feature of reality that is independent of us. ${ }^{6}$

For The Dynamic Theory of Time, on the other hand, the guiding thought is that time is very different from space, in a number of ways. Opponents of The Dynamic Theory (and sometimes proponents as well) like to characterize the theory using the metaphor of a moving spotlight that slides along the temporal dimension, brightly illuminating just one moment of time, the present, while the future is a kind of foggy region of potential and the past is a shadowy realm

\footnotetext{
${ }^{6}$ See for example Paul 2010.
} 
of what has been. But it is important to understand that while the moving spotlight is an intuitively appealing way to capture the idea behind The Dynamic Theory, in the end it is just a metaphor. What the metaphor represents is the essential idea behind The Dynamic Theory, namely, the idea that being future, being present, and being past are objective and metaphysically significant properties of times, events, and things. Also, the metaphor of the moving spotlight represents the fact that according to The Dynamic Theory, each time undergoes a somewhat peculiar but inexorable process, sometimes called temporal becoming. It goes from being in the distant future to being in the near future, it has a brief moment of glory in the present, and then it recedes forever further and further into the past.

Despite its being intuitively appealing (especially for Static Theorists, who see it as a caricature of The Dynamic Theory), the moving spotlight metaphor has a major drawback: It encourages us to think of time as a fourth dimension, akin to the dimensions of space. But for The Dynamic Theory, as I am understanding it, this way of thinking - "spatializing time" - is a major no-no. On The Dynamic Theory, it is not that there are these four similar but orthogonal dimensions, which together make up a unified manifold, and one of which just happens to have some extra bells and whistles (like a moving spotlight) added to it. Instead, it is that time is completely different from the dimensions of space. So different, in fact, that it is a completely different kind of dimension. For time (on The Dynamic Theory) is more similar to modality or morality than to space: we can call it a dimension, but it would be a mistake to think of it as one of several similar dimensions that together make up a unified manifold that contains the physical universe. ${ }^{7}$

Here is the view. ${ }^{8}$ (Important note: the different components I am building into The Dynamic Theory need not all be combined in this way. There are various "mix and match" combinations that are possible (some of which have been explicitly endorsed). But this

${ }^{7}$ For a recent argument against the claim that time and space form a unified manifold of orthogonal dimensions, see Markosian 2020.

${ }^{8}$ Some or all of the following components of The Dynamic Theory can be found in Prior 1967, Thomson 1983, Markosian 1993 and 2004, and Sullivan 2012. (Not to mention many other places.) 
particular combination is among the most popular in the literature, and is arguably the most interesting. In any case it is the combination that I endorse, and the one that I will be discussing in this paper.)

The Dynamic Theory of Time

1. Time cannot be added to the dimensions of space to form a unified manifold in which physical objects are located and possibly extended.

2. Any physical object that persists through time does so in virtue of being wholly present at each moment at which it is present. ${ }^{9}$

3. There are genuine and irreducible $A$-properties, which cannot be correctly analyzed in terms of $B$-relations.

4. The temporal facts about the world include ever-changing facts involving A-properties, including facts about which times are past, which time is present, and which times are future.

5. We must take tense seriously. Propositions have truth values at times rather than simpliciter and can, in principle, change their truth values over time. Also, we cannot eliminate verbal tenses like is, was, and will be from an ideal language.

6. The correct ontology is liable to change over time, and it is always true that only present objects exist.

I want to offer two better metaphors for capturing our two theories of time. For The Static Theory, the universe is like a movie that is never shown. The frames are all there, but the movie is just sitting on a shelf. Also, instead of being attached end to end, in the normal way of filmstrips, the frames are cut, and then stacked one on top of another (in chronological order). Each frame is a temporal slice of the world, and if you look closely at the stack of frames, you can see the various objects - each of which is a "spacetime worm" curving through the continuum that is spacetime. (It helps if you turn the stack sideways, so that earlier frames are to the left of later

${ }^{9}$ For a definition of 'wholly present' see Markosian 1994: 248. 
frames.) Importantly, on The Static Theory, because the movie is never shown, no part of it is metaphysically privileged. There is no light shining on any one frame. No frame is special.

For The Dynamic Theory, on the other hand, the universe is like a movie that is being shown in a theater right now. And, crucially, it's not the frames in the filmstrip that are the universe: it is the image on the screen. There is only one image on the screen, and it keeps changing. That's because reality is one thing that keeps changing. It was that way, and now it is this way. Soon it will be some other way.

The frames in the filmstrip up in the projection booth are a useful way to represent the different states of the universe at different times, on The Dynamic Theory. They are like maximal, consistent, tensed propositions. There is always one of them that is special: the one that corresponds to the image on the screen right now. But it is important to understand that which frames are in the filmstrip, and which one has a light shining through it right now, is determined by the universe, and not the other way around. (So this is an important disanalogy between the universe and a movie being shown in a theater, on The Dynamic Theory.)

This pair of movie theater metaphors to capture the two theories of time is essential to my preferred way of thinking about The Dynamic Theory and its rival, The Static Theory; and the metaphors will play an important role in the arguments below. But before I get to the problems with The Dynamic Theory and time travel to the past, let me first say something about time travel on The Static Theory of Time.

\section{Time travel and the static theory of time}

The Static Theory is normally thought of as being consistent with the possibility of traveling in time, and indeed Static Theorists love to theorize about time travel. ${ }^{10}$ The key, for Static Theorists, is that a time traveler is defined as someone whose personal time disagrees with external time. ${ }^{11}$ External time is the normal, objective, temporal

\footnotetext{
${ }^{10}$ See for example Lewis 1976, Vihvelin 1996, Sider 2002, Dyke 2005, Miller 2017 and Bernstein 2015.

${ }^{11}$ This definition of time travel and the following definitions of 'personal
} 
order experienced by non-time-travelers everywhere. Your personal time, on the other hand, is the series of times that results from ordering the events in your life according to standard causal patterns, so that eating precedes digestion, and so on. If you eat a sandwich before getting into your time machine in 2020, and then digest that sandwich after your arrival back in 1920, then your personal time is ordered accordingly. And, in that case, since your personal time would disagree with external time, you would be a time traveler.

But what makes it true that that person popping into existence in 1920 with the sandwich in her stomach is you, according to the Static Theorist? The answer is that it's a little bit complicated. Here is a short version of the account favored by David Lewis and many other Static Theorists. We start with facts about all of the qualities distributed over spacetime. Next we identify the most basic patterns displayed by the distribution of these qualities. These most basic patterns are the laws of nature. Then we use the laws to determine which events are causing which events, and which temporal parts are related to which other temporal parts by the different temporal parts of the same object relation. Once these facts are fixed, we get facts like the fact that that person stage in the time machine in 1920 is a part of the same person as this other person stage in the time machine in 2020. And finally, we order all of the person stages of one person according to the standard causal patterns - with eating preceding digestion - in order to get each person's personal time. So on The Static Theory, as long as we have the right person stages with the right properties at the right times, so that we have some people whose personal times disagree with external time, there can be time travelers.

One possible response to this line of reasoning from the Static Theorist is, "That all sounds great, although there remains a troubling question: Why do we not see time travelers from the future? They would after all be easy to recognize, because they would all wear the same monochromatic outfits. And yet we do not see this. Strange!"12

time' and 'external time' are from Lewis 1976: 146.

${ }^{12}$ For the record, I do not endorse the argument suggested here. I think our failure to spot time travelers from the future is at best a small piece of defeasible evidence against the possibility of time travel to the past. But there are other possible explanations for our not seeing time travelers from the future. Perhaps they 
I think the explanation for this apparent mystery is that The Dynamic Theory of Time is true, and also that The Dynamic Theory is inconsistent with the possibility of time travel to the past. In the next four sections I will explain why.

\section{The rubber duck argument}

The first reason why The Dynamic Theory is inconsistent with the possibility of time travel to the past is that if The Dynamic Theory is true, then personal time is a rubber duck - it sounds like it is a type of time, but it's really not. Here is why this is relevant. The Static Theorist is correct to say that someone's adventures should count as traveling in time only if her personal time disagrees with external time. But an important corollary of this conception of time travel is that time travel is possible only if personal time is sufficiently like external time to deserve the name time. And if The Dynamic Theory is true, then personal time is not sufficiently like external time to deserve the name time. For personal time lacks pizzazz. The reason personal time lacks pizzazz is that there is no equivalent of the (metaphorical) moving spotlight for personal time. That is, there is no special property of presentness that is instantiated by one special time, and then instantiated by another time, and so on. Without that feature, personal time, on The Dynamic Theory, is just an alternative way of lining up the events in someone's life; but it does not give us something that is sufficiently like time to deserve the name time.

Here is an example to illustrate my point. Suppose you are playing a game. The game is made up of a series of discrete moves, each of which starts from the same position. There are 26 types of moveA-type moves, B-type moves, etc. - with a billion instances of each type. Normally people playing the game first perform an A-type move, then a B-type move, etc. But that is not required by the rules. So you perform a series of moves in the game. It's a series that, given the way people normally play this game, looks quite bizarre. You first perform a J-type move, followed by an S-type move, and then an A-type move, etc. Also, in addition to looking bizarre, your series

don't choose to visit our troubled era, with its widespread injustice. Or perhaps they do, but are careful to blend in. 
of moves in the game constitutes a poor effort, worthy of a very low score in the game. But suppose it just so happens that if your moves are re-ordered in the normal way, like a video being re-spliced, so that your A-type move comes first, and is followed by your B-type move, which is followed by your C-type move, etc., then your series of moves constitutes the most brilliant and high-scoring game ever played.

Does the fact that when your moves are re-ordered in this way they disagree with their ordering in external time mean that you are a time traveler (who has in fact played the most brilliant game of this kind ever)? I don't think so. I think it just means that the series of moves that you actually performed has a peculiar feature. It is a series that looks weird, but can be made to look normal by re-splicing. And the reason you are not a time traveler, despite the fact that your series of moves has this strange feature, is that there is nothing special about the particular way of re-ordering your moves that makes them look like a brilliant playing of the game. It is not a metaphysically privileged way of ordering the relevant events - it is just one of many possible ways that those events could be ordered.

We might say that that way of ordering your moves in the game corresponds to your "standard-game time" (by analogy with personal time), but it doesn't follow that there is anything metaphysically significant about that way of ordering the events. Nor does it follow that there is a special kind of time associated with that way of ordering your moves.

I think it's the same with personal time. We can re-order the events of the time traveler's life according to commonly seen patterns for those events, and it is remarkable that when we do so, we get an ordering that differs from the ordering of those events in external time. But it doesn't follow that there is a special kind of time associated with the relevant ordering of the events of the time traveler's life.

You might wonder what would make some particular way of ordering a series of events sufficiently like external time. Easy: there would have to be something equivalent to a moving spotlight that follows that particular way of ordering those events. That is, there would have to be a "moving flashlight" for the time traveler's personal time. It would start at her birth, and move up to the moment when she pushes the button in the time machine. Then it would jump back to the much earlier arrival in the time machine. And this moving flashlight would 
represent a metaphysically significant, temporal property, just like presentness, that moves across the events of the time traveler's life, but in a way that is out of sync with the grand moving spotlight.

But of course there is no such moving flashlight, because there is no metaphysically significant, temporal property that moves across the events of the time traveler's life in a way that is out of sync with the grand moving spotlight. The Dynamic Theory entails that there is a dynamic aspect to external time, but it does not entail that there is an additional dynamic aspect to each individual's personal time. Nor is it in any way plausible to posit such a dynamic aspect to anyone's personal time, as a metaphysical add-on to the Dynamic Theory. Which is why personal time is a rubber duck - it's called "time" but it's not really time.

Here is my argument. ${ }^{13}$

\section{The Rubber Duck Argument}

(1) If time travel is possible, then whether you are a time traveler depends on whether your personal time disagrees with external time.

(2) If whether you are a time traveler depends on whether your personal time disagrees with external time, then personal time must be sufficiently like external time to deserve the name time.

(3) The Dynamic Theory entails that personal time is not sufficiently like external time to deserve the name time. ${ }^{14}$

(4) The Dynamic Theory entails that time travel is not possible.

\footnotetext{
${ }^{13}$ Theodore Sider offers a broadly similar argument, but one that differs in certain details, in Sider 2005.

${ }^{14}$ John W. Carroll has suggested in correspondence that there may be a similar issue for The Static Theory of Time, which would mean that it too is incompatible with the possibility of time travel. I am sympathetic to this suggestion, but will not explore it here, since my aim in this paper is merely to argue that The Dynamic Theory, at least, entails the impossibility of time travel.
} 
(I note that this argument works equally well against the possibility of time travel to the future.)

There is a natural objection to this argument that will have occurred to some readers. The objection begins by pointing out that it is the causal relations among the events of the time traveler's life that generate the ordering of those events in the time traveler's personal time. For example, the time traveler's eating a sandwich right before pushing a button and then disappearing in 2020 causes the digesting events in the time traveler's stomach in 1920; and this is precisely why the eating event precedes the digesting event in her personal time.

So far, so good. The next part of the natural objection involves the thought that ordering a series of events (like those of the time traveler's life) according to the causal relations among those events is in no way arbitrary, and in fact gives us a very time-like ordering, insofar as the notions of causation and time have long been thought to be inextricably linked. ${ }^{15}$ Thus, according to the objection, personal time is, after all, sufficiently like external time to deserve the name time.

My reply to this objection is that it works only if we assume The Static Theory of Time. For on The Dynamic Theory, there are important facts about time that are not captured merely by the fact that moments of time (and events in time) are ordered in a certain way. It is also essential to time - and hence to being sufficiently like timethat there is a dynamic aspect to the temporal dimension. This is what is captured by the moving spotlight metaphor, and it is what is captured in a non-metaphorical way by the claim that there are genuine and irreducible facts about A-properties, which keep changing in an inexorable way, no matter what anyone does. And this is why we would have to make the absurd posit of a moving flashlight for the time traveler's personal time in order for personal time to be sufficiently like external time. Without a moving flashlight - without a special property that attaches to the moments of personal time, in a way that keeps changing inexorably_- personal time remains just an interesting, alternative way of ordering a bunch of events.

\footnotetext{
${ }^{15}$ The so-called causal theory of time has a long history. See for example Kant, Critique of Pure Reason, Transcendental Analytic, Book II, Chapter 2, Section 3B; Reichenbach 1956: 32-42, and Mellor 1998: Chapter 10.
} 


\section{No backward causation}

The second reason why The Dynamic Theory is inconsistent with the possibility of time travel to the past has to do with backward causation. To be a real time traveler, who travels, say, from 2020 back to 1920 , your pushing the button in your time machine in 2020 must cause your appearance in 1920. Without that detail, it is not a story about time travel. But The Dynamic Theory entails that this kind of backward causation is impossible. That is, The Dynamic Theory entails the following thesis.

No BACKWARD CAUSATION: Causes can never occur after their effects.

And here is why The Dynamic Theory entails No BACKWARD CAUSATION. To cause some event is to make it happen. But The Dynamic Theory entails that there is a crucial distinction between an event's going to happen, its happening, and its having happened. This is part of the Dynamic Theorist's claim that we must take tense seriously (a.k.a. the fifth component of The Dynamic Theory), and it is a result of the real and objective distinctions made by the theory between past, present, and future (in the third and fourth components of the theory).

On The Static Theory, of course, there are no such distinctions. All the events are there, in a four-dimensional spread. Each event stands in various B-relations to other events. And that is all there is to time. Meanwhile, since, according to The Static Theory, the facts about causation are a function of the pattern of distribution of qualities over spacetime, it turns out that there are no a priori rules about how causation can work. This is why The Static Theory is consistent with backward causation.

But on The Dynamic Theory, there is a great deal more to time. One way to see this is in terms of the movie metaphor. Think of the universe as a changing image on a movie screen. Let there be a scene in the movie that is the appearance (seemingly from nowhere) in 1920 of a woman in a time machine. And let this scene be followed immediately by scenes of this woman's having various adventures, until eventually she dies of old age in 1980. (It's a really long movie.) Let there also be a scene in 1990 that is the birth of a baby girl, which scene is followed in the movie by her growing up, building a time machine, getting into the machine in 2020, setting the dials for 
1920, and then disappearing. And, finally, let the woman who disappears in 2020 be just like the woman who appears in 1920. (Similarly with the time machine in 2020 and the one in 1920.)

Now suppose we are watching the movie, and are right at the moment featuring the woman in the time machine in 2020. Suppose we see her, up on the screen, reaching for the button. And ask yourself whether this imminent event - her pushing the button — is going to cause that earlier event - the appearing from nowhere event in 1920, the one involving a woman just like her. Given that the appearing from nowhere event of 1920 already happened in the movie many years ago, it seems like the answer must be, No, this woman's pushing the button now cannot possibly make that earlier event happen, because the earlier event was part of a scene that has already happened. It's past.

Notice that even without the movie metaphor, it remains true (according to The Dynamic Theory) that there is a fundamental, unanalyzable difference between some event e's going to happen, e's happening, and e's having happened. And this difference is the crucial difference between what is future, what is present, and what is past. On The Dynamic Theory, there are real, objective facts about these matters. There is a genuine and metaphysically significant difference between past, present, and future. And a crucial consequence of this distinction is that once an event has happened, it is too late to make it happen. The past is over.

So the American writer William Faulkner had it completely wrong when he wrote "The past is never dead. It isn't even past." 16 This is a beautiful way to capture The Static Theory of Time- but if The Static Theory is false, as I believe it is, then this is a beautiful way to capture a deeply mistaken idea about time. ${ }^{17}$ Meanwhile, the Irish folk singer Phil Coulter was on the right track when he wrote "For what's done is done and what's won is won, And what's lost is lost and gone forever." ${ }^{18}$ These are beautiful words, too, even though

${ }^{16}$ Faulkner, Requiem for a Nun, p. 73.

${ }^{17}$ Also, to be fair to Faulkner, this idea is probably not what he actually had in mind when he wrote this line. I suspect that what he actually had in mind is something that is consistent with The Dynamic Theory, namely, the idea that traces of past events are always with us.

${ }^{18}$ Coulter, The Town I Loved So Well, 1973. 
the idea they express is a metaphysically significant but deeply sad fact about reality.

Here is what I take to be the upshot of these remarks: Reality is tensed. There is only one image - the one on the screen - and it keeps changing. But once an event has happened, and is in the past - once a scene has appeared on the screen - it is thereafter too late to make it happen. That would be like trying to create a thinga building, say - that already exists. For once a building exists, it is too late to bring it into existence. The argument can be formulated as follows.

\section{The No BACKWARD CAUSATION Argument}

(1) To cause an event is to make it happen.

(2) The Dynamic Theory entails that once an event has happened, it is too late to make it happen.

(3) The Dynamic Theory entails that backward causation is not possible.

(4) Time travel to the past is possible only if backward causation is possible.

(5) The Dynamic Theory entails that time travel to the past is not possible.

Here is a likely objection: This means that The Dynamic Theory is incompatible with certain theories of causation (like Counterfactual Dependence) and certain general pictures of how causation works (like the Lewisean "Humean Supervenience" picture), which allow for the possibility of backward causation. ${ }^{19}$

My reply is that I plead guilty. The Dynamic Theory does entail the substantive claim that there is more to causation than counterfactual dependence. For counterfactual dependence can hold between

${ }^{19}$ On Counterfactual Dependence see Lewis 1973. On Humean Supervenience see Lewis 1994. 
an event and a later event, and The Dynamic Theory entails No BACKWARD CAUSATION. (Similarly with The Dynamic Theory and the general Humean Supervenience picture.)

Mind you, it's not that there aren't any possible worlds like the ones envisioned by the Static Theorist with a Lewisean account of time travel. It's just that those are not genuine time travel worlds. For consider one of those worlds. Let it be an ideal scenario for the Static Theorist. A person in a strange machine pops into existence, seemingly from nowhere, in 1920, with lots of memory impressions that seem to be from 2020 of building a time machine, setting the dials for 1920, and pushing the button. That person lives out her days in the $20^{\text {th }}$ Century, and then dies. Later, a girl is born, grows up, and in 2020 builds what looks like a time machine. She sets the dials for 1920. And as she pushes the button, she happens to be just like the woman who popped into existence back in 1920. Then she and her machine disappear.

This is a world with some amazing happenings and coincidences. It's an amazing happening that this woman and her machine popped into existence when they did, out of nowhere, in 1920. It's an amazing coincidence that the later woman with the alleged time machine in 2020 ended up being just like the miracle woman who popped up in 1920. And it's an even more amazing coincidence that, right when the later woman with the alleged time machine came to be qualitatively identical to the woman who popped into existence in 1920, she (the later woman) suddenly popped out of existence!

But this is not a time travel world (on The Dynamic Theory), because the woman's pushing the button in 2020 did not cause the appearance of the woman and the machine in 1920. This is guaranteed to be true (again assuming The Dynamic Theory) because of No BACKWARD CAUSATION.

\section{Only one next}

My third reason for thinking that The Dynamic Theory of Time is inconsistent with the possibility of time travel to the past is that there is only one next. The idea behind this argument is similar to that behind The Rubber Duck Argument, but it is more of a big picture point. One way to make the point is in terms of the movie metaphor. 
Imagine that we are watching the movie, and that it depicts what counts as an ideal time travel scenario, according to The Static Theorist. First we saw an apparent time traveler popping into existence. Then we saw her living out her days in a constant state of amazement over how old-timey everything was. How fun that was for her! Then we watched her dying of old age, in 1980. After that we saw a girl being born in 1990. Then we watched the girl growing up and building a time machine. And now we see her getting into the machine and reaching for the button. What will happen next? Will she travel back in time? Will she next exist in 1920?

The answer is No. Many people existed in 1920, including the apparent time traveler, who looked just like this woman on the screen now. (Remember when we saw that woman back there, right here on this screen? How exciting that was!) But what will happen next is that the movie will continue with the current scene, the way it always and inexorably does. What will happen next with respect to the would-be time traveler on the screen right now is that she and her misleadingly labeled "time machine" will disappear, never to be seen again. Unlucky! What will definitely not happen next is that the image on the screen will shift back to 1920 so the would-be time traveler can experience all of that. For (and here is the crucial point) the universe is a movie without flashbacks. It is a movie in which the story always progresses forward in time. So if the current image on the screen is of a woman in a machine about to push a button, and if the next image will show that the woman and the machine have disappeared, then what will happen next is that she will be gone. Even if there was an earlier scene in which someone like her in a machine like that popped into existence seemingly from nowhere, that does not make it true that what will happen next (in the image on the screen, which is the one and only reality) is that earlier scene. So what will happen next is that the other people on the screen will be standing around saying, "I wonder what happened to her!"

The upshot of these considerations is that it is not possible for her to go back to 1920. She, like the rest of us, can only go forward. Here is the argument. 
The "Only One Next" Argument

(1) If someone is about to travel back in time, then it must be true (in some important sense) that what she will experience next is an event in the past.

(2) The Dynamic Theory entails that it is never true (in any important sense) that what someone will experience next is an event in the past.

(3) The Dynamic Theory entails that time travel to the past is not possible.

It might be objected that there is an important sense in which what will happen next is that the woman who is about to push the button will experience popping into existence, seemingly from nowhere, back in 1920. For that is what will happen next in her personal time. This would be a good objection if The Static Theory were true. But we are now supposing that The Dynamic Theory is true, which means that there is only one reality (namely, the changing image on the screen). And it is because of this crucial fact that there is only one important sense of next, namely, what will happen next in the one and only reality.

\section{Other times are not possible destinations}

My fourth reason for thinking that The Dynamic Theory of Time is inconsistent with the possibility of time travel to the past, unlike the previous three reasons, depends crucially on the fact that I have built Presentism into my characterization of The Dynamic Theory (as the sixth tenet of the theory). Since some philosophers who endorse the other five tenets of The Dynamic Theory do not also endorse Presentism, this is worth flagging at the outset. (So please consider there to be a warning flag placed right here.)

We have seen that the reason The Static Theory is so amenable to the idea of time travel is that it spatializes time - it makes time one of four more or less similar dimensions in which the physical universe is spread out. This means that, setting aside problems about 
whether the laws of nature permit this, it is theoretically possible for an object like you or me to move around in the four-dimensional manifold in a way that satisfies Lewis's definition of time travel. For we are, on this view, just a bunch of people sitting around in a fourdimensional manifold, and we can therefore think about getting up and moving to a different location in the manifold.

But of course on The Dynamic Theory, other times are not locations in a manifold. You might therefore wonder: What are other times, on The Dynamic Theory, if they are not locations in a manifold? This is an important question, and there are many different possible answers available to the Dynamic Theorist. A proper treatment of the issue would be beyond the scope of this paper, but in what follows I will summarize my favorite answer to this question. I take it to be a fairly representative account of other times, according to The Dynamic Theory, and I think that alternative Dynamic Theory accounts of other times would give rise to the same argument against time travel that I am going to give in this section, but I will not pursue that question here. So please consider the argument of this section to be more conditional than the previous arguments I have given: for it is conditional on including Presentism in The Dynamic Theory, and also on one particular way of accounting for other times, given the constraints of Presentism.

Recall that on The Dynamic Theory, time is more like modality than it is like space. And notice that modality is not a dimension in the manifold that houses our physical universe. Modality is a way of talking about how things might have been. Other possible worlds are best thought of as maximal, consistent ways things could be. They are enormous propositions. ${ }^{20}$

$w$ is a possible world $=_{\mathrm{df}} w$ is a maximal, consistent proposition.

Likewise, time is a way of talking about how things have been and will be. ('I reached home at noon yesterday' is a way of saying that $x$ number of hours ago I reached home.) So times, on the view that I like, are best thought of as maximal, consistent, present-tensed

\footnotetext{
${ }^{20}$ This is one of several standard conceptions of possible worlds for those who do not accept David Lewis's modal realism. See Plantinga 1974, Prior and Fine 1977, Lewis 1986 and Menzel 2018 for some discussion of similar views.
} 
propositions. But they are the ones that have been true, are true, or will be true.

$t$ is a time $=_{\mathrm{df}} t$ is a maximal, consistent, present-tensed proposition that has been true, is true, or will be true. ${ }^{21}$

The present time is the one maximal, consistent, present-tensed proposition that is true right now. (Just as the actual world is the one maximal, consistent proposition that happens to be true.) The time 10 years from now is the maximal, consistent, present-tensed proposition that will be true 10 years from now. And similarly with other past and future times. They are like possible worlds - they are all logical constructs out of propositions.

Because times (like possible worlds) are logical constructs out of propositions, they are not possible travel destinations. You cannot travel to another possible world, because it is a logical construct, rather than a concrete place. And you cannot travel to another time for the same reason. Here then is the argument.

The No-Destination Argument

(1) The Dynamic Theory entails that other times are logical constructs rather than locations in a manifold.

(2) If other times are logical constructs rather than locations in a manifold, then other times are not possible travel destinations.

(3) If other times are not possible travel destinations, then time travel is not possible.

(4) The Dynamic Theory entails that time travel is not possible.

It should be pointed out that this argument (like The Rubber Duck Argument) works equally well against the possibility of time travel to the future. It is also worth noticing that there is a modal analogue of The No-Destination Argument, with the conclusion that Modal

${ }^{21}$ See for example Prior and Fine 1977, Markosian 2004: Section 3.10, and Emery 2017. 
Actualism entails that modal travel is impossible. I would endorse that argument, too, as would nearly every philosopher who is not a modal realist. (While most modal realists, like David Lewis, would argue that modal travel is impossible for other reasons. Modal travel is not nearly as popular a concept as time travel.)

It is worth re-emphasizing that this argument depends crucially on the sixth component that I have built into The Dynamic Theory of time, namely, Presentism. So the argument will not apply to those who endorse a view consisting of only the first five tenets of the view that I am calling The Dynamic Theory. Notice also that the argument is distinct from an argument that one sometimes encounters, according to which Presentism is inconsistent with the possibility of time travel because it entails that the past and the future do not exist. ${ }^{22}$ For according to what I have just said, past and future times do exist - the problem, instead, is that they are not suitable travel destinations.

\section{A surprising corollary}

There is a surprising corollary of the above arguments. If I am right about any of these arguments, then The Dynamic Theory of Time entails that time travel to the past is metaphysically impossible. So if we encounter people who seem to be time travelers from the future-people who show up with a strange but credible story about how they come from the future (not to mention the monochromatic outfits) - then we would have excellent empirical evidence against The Dynamic Theory. This means that The Dynamic Theory of Time, unlike many metaphysical theories, is empirically falsifiable. ${ }^{23}$

${ }^{22}$ Keller and Nelson criticize such arguments in their 2001.

${ }^{23}$ There is a slight complication here. I happen to be convinced, by anti-skeptical arguments like those found in Markosian 2014, that I do in fact know that I am not a brain in a vat. But if I encountered apparent time travelers with a plausible story, as described above, then I would probably not conclude that The Dynamic Theory is false. Instead, I would probably conclude that I am a brain in a vat after all (and I would tip my hat to my alien overlords for making the illusion they are feeding me so interesting). 


\section{Don't push that button!}

Suppose I am wrong about all of the above. Suppose personal time (even on The Dynamic Theory) is sufficiently like external time to make it deserve the name time. Suppose backward causation is possible (even on The Dynamic Theory). Suppose the fact that there is only one next is somehow not enough (even on The Dynamic Theory) to make it true that you can't travel back in time. And suppose that (even on The Dynamic Theory) other times somehow are possible travel destinations. I think there is still a good reason why you should not want to travel back in time, given The Dynamic Theory of Time.

In order to see why, return to our story of a woman who travels back in time from 2020 to 1920 . And consider two different contexts in which you could be advising someone about what to choose. The first context is an extra-world context, like the situation Atlanta finds herself in in Plato's Myth of Er, in Book X of The Republic. Atlanta, in that situation, was choosing an entire life, all at once. (In the story, Atlanta was able to view a bunch of different lives that were available to her. The different lives were displayed on the ground in front of her like little holograms. She ended up choosing the life of a great athlete who - unlike herself in her previous life — was allowed to participate in athletic competitions and win prizes and glory.) The second context in which you could be advising someone is an intra-world context. In this kind of situation, you are offering advice to someone about choosing how to continue the life that they are already living. (This is how we normally advise our friends.)

Now think about how we would advise our heroine from the time travel scenario in an extra-world context. "Go for the time travel world," we would say to her. "That would be so much fun! You will experience the same amount of life, altogether, but with your experiences in a weird order. Your personal time will disagree with external time, but you will still have a full lifetime's worth of experiences, and many of them will involve experiencing life as a time traveler. It will be awesome!" (Keep in mind that we are here setting aside the previous four arguments against the possibility of time travel to the past.)

And now think about how we would advise our heroine in an intra-world context. Suppose that she has climbed into a machine 
that she built, with a dial set for 1920, and she is contemplating pushing the big red button. "What do you think I should do?" she asks us. Our reply should be, "Stay alive, no matter what occurs!" For it doesn't matter (much) what happened 100 years ago. What matters is what will happen next. (This point is closely related to The "Only One Next" Argument.)

The reason for this difference in how we would advise our heroine in extra-world versus intra-world contexts is that when we are in the middle of living our lives, we have a bias toward the future. We also have biases toward the present, and toward the near future over the distant future. These well-known time-biases are sensible, given The Dynamic Theory of Time. (But maybe not so sensible on The Static Theory. $)^{24}$

And here is why all of this is relevant. When you are making decisions, you are always in an intra-world context. You are always deciding how to continue the life that you are already living. So as you sit in the time machine (which we are no longer supposing to be a misleadingly labeled annihilator), you are making an intra-world decision, about what will happen to you next. And the best decision for you, like the best decision for our heroine in an intra-world context, is not to go out of existence forever. (No matter what has happened in the past.) For here is what is true, on our suppositions, and in the relevant situation: If you push the button, then that person in the past (whose experiences do not now benefit you in any practical way, since you have no memory of them) will have been you, and you will be a time traveler, but you will now go out of existence forever. And if you don't push the button, then that person in the past will not have been you (but will have been an amazing coincidence), you will not be a time traveler, and you will continue to exist for a good long time. My advice to you, in this situation, is what I suspect any kind person would advise in such an intra-world context: Don't push that button!

Here is the argument suggested by these considerations.

${ }^{24}$ On various problems relating to our time biases see Sullivan 2018. 
An Argument Against the Advisability of Traveling Back in Time

(1) The Dynamic Theory of Time entails that leaving the present to go back to the past involves permanently going out of existence.

(2) Permanently going out of existence in order to ensure the truth of some propositions about yourself in the past is not an advisable tradeoff.

(3) If (1) and (2), then The Dynamic Theory entails that traveling back in time is not advisable.

(4) The Dynamic Theory entails that traveling back in time is not advisable.

This argument comes with three main caveats. The first is that, like The No-Destination Argument (and unlike the first three arguments I have given), it depends on including Presentism as a part of The Dynamic Theory. The second caveat is that this argument does not apply to all cases of time travel to the past. For if you have excellent evidence that you will not be making a one-way trip to the past, but will, for example, spend a month in 1920 and then return to the present time (or even some time in the near future), then pushing the button in the time machine will not (according to your evidence) lead to your permanently going out of existence. (There may of course be questions about whether the true account of personal identity for human people like ourselves allows for periods of temporary non-existence, but let us set that issue aside.) So the above argument applies only to cases of one-way time travel to the past. The third caveat is that in some cases it is advisable to permanently go out of existence. For if conditions in the world and in one's life have become so bad that one's life is worse than non-existence, then all bets are off. But if we assume that you are living a life that is worth living, and if we assume we are talking about one-way time travel to the past, then time travel to the past is clearly inadvisable on The Dynamic Theory. 
10 What are we thinking about when we think about time travel to the past?

If what I have said above is correct, and if The Dynamic Theory of Time is true, then there is something very puzzling going on when we think about time travel to the past. For if The Dynamic Theory is inconsistent with the possibility of this kind of time travel, and if The Dynamic Theory is true, then such time travel is not metaphysically possible. This raises a question: What are we imagining when we imagine time travel to the past? It certainly doesn't feel like we are imagining something impossible.

Here is the first part of my answer to this question. I think that for many depictions of time travel in, for example, books and movies, we are simply being told a story with flashbacks. What's more, in the story, the empirical details are just as the Static Theorist would like them to be, in order to be a case of time travel. And the characters in the story often accept that theirs is a genuine case of time travel. But of course there is no way for the fiction really to depict things as being a genuine case of time travel, whether time travel is possible or not. A fiction cannot somehow depict that the metaphysical facts are a certain way. So on my view, these are stories, told with flashbacks, of people who mistakenly think they are time travelers (or mistakenly think they are dealing with time travelers), when they're really not. ${ }^{25}$

That's fine, you might think, but what about the fact that we can imagine ourselves traveling back in time? When you imagine a time travel story in the first person, you are imagining a series of events, seen from a first-person perspective: "First I am building the time machine. Then I am setting the dials. Then I am pushing the button in 2020 and, next, finding myself in the year 1920." And yet, if I am right, and if The Dynamic Theory is true, then what seems like a perfectly possible series of experiences, imaginable by a six-year old, is in fact not possible after all. And yet it feels possible. What's up with that?

\footnotetext{
${ }^{25}$ Bourne and Caddick Bourne offer a similar account of what is happening when third-person fictions appear to portray certain kinds of time travel stories that they take to be impossible (for reasons of their own). See their 2016: 129ff.
} 
The answer (and this is the second part of my response to the general challenge about why we can effortlessly entertain time travel stories, if what they depict is metaphysically impossible) is that when you imagine such a series of experiences, you are not really imagining yourself being time a traveler. Instead, you are imagining pushing a button and then continuing to exist while everything around you pops out of existence, and a whole bunch of things just like the things that existed in 1920 pop into existence. And while all of this is happening, reality keeps humming along, right through the shocking disappearance of everything but you in 2020 and the simultaneous appearance of a whole lot of 1920-looking things. This is of course a pretty bizarre scenario, and probably not one that you actually want to wish for, since it involves all of your friends and loved ones popping out of existence. But at least it is metaphysically possible, which is why you can imagine it.

\section{Conclusion}

In this paper I have discussed two popular theories of time, each one consisting of a package of specific theses that are related, but not essentially tied together. These two theories are not the only theories of time, or even the only popular theories of time. (Although I suspect that they happen to be the two most popular theories among contemporary metaphysicians.) One of the two theories discussed here - what I have called The Static Theory of Time - was considered mainly in order to contrast it with the theory that my arguments focused on, the view that I called The Dynamic Theory of Time. So the fact that there are alternatives to The Static Theory, as I have presented it here (that is, other packages that contain some but not all of the specific components of the package I have identified), does not have any bearing on the arguments of this paper.

But it is of course relevant that there are alternatives to The Dynamic Theory of Time, as I have presented it here, since my arguments have focused on that particular package of views. Still, the only component of The Dynamic Theory, as it is presented here, that anyone with Dynamic Theory sympathies is likely reject is the sixth one, namely, Presentism. So it is worth pointing out that only two of the five arguments offered in this paper-The No-Destination 
Argument and An Argument Against the Advisability of Traveling Back in Time- depend on including Presentism in the package of views that I have called The Dynamic Theory of Time. Which means that the other three arguments presented in this paper-The Rubber Duck Argument, The No BACKWARD CAUSATION Argument, and The "Only One Next" Argument — will all apply to the other popular versions of The Dynamic Theory of Time. So if you believe that time is significantly different from space, that physical objects do not have temporal parts, that there are genuine and irreducible A-properties (which cannot be correctly analyzed in terms of B-relations), that the temporal facts about the world include ever-changing facts involving $A$-properties, and that we must take tense seriously, then you should believe that it is impossible to travel back in time. Moreover, if you believe all of the components of what I have called The Dynamic Theory of Time (including Presentism), but still think for some reason (despite all of my arguments) that it is possible to travel back in time, then you should nevertheless not want to travel back in time. So I end with the same advice that I gave above: Don't push that button! ${ }^{26}$

Ned Markosian Department of Philosophy University of Massachusetts Amherst markosian@umass.edu

\section{References}

Bernstein, S. 2015. Nowhere man: time travel and spatial location. Midwest Studies in Philosophy 39: 158-68.

Bourne, C. and Caddick Bourne, E. 2016. Time in Fiction. Oxford: Oxford University Press.

${ }^{26}$ I am very grateful to John W. Carroll, Nina Emery, Dan Korman, Irem Kurtsal, Rebecca Mason, Chris Meacham, Carla Merino-Rajme, Thomas Ryckman, Ted Sider, Bradford Skow, Mark Steen, Meghan Sullivan, and an anonymous referee for helpful comments on earlier versions of this paper. I am also grateful to audiences at the 2017 New England Workshop on Philosophy of Time, The University of Lisbon, the 2017 Central Division Meeting of the APA, The University of Milan, The University of Illinois, The University of Alabama, Yerevan State University, Boğaziçi University, The University of Barcelona, The Massachusetts Institute of Technology, Lawrence University, and the 2012 Rome Science Festival. 
Dyke, H. 2005. The metaphysics and epistemology of time travel. Think 9: 43-52.

Emery, N. 2017. Temporal ersatzism. Philosophy Compass 12: 1-13.

Emery, N. 2019. Actualism without presentism? Not by way of the relativity objection. Nous 53: 963-86.

Faulkner, W. 1951. Requiem for a Nun. New York: Random House.

Hawley, K. 2001. How Things Persist. Oxford: Oxford University Press.

Hinchliff, M. 2000. A Defense of presentism in a relativistic setting. Philosophy of Science 67: S575-86.

Kant, I. 1781. Critique of Pure Reason. Translated by N. Kemp Smith. London: Macmillan Press, 1965.

Keller, S. and Nelson, M. 2001. Presentists should believe in time travel. Australasian Journal of Philosophy 79: 333-45.

Lewis, D. 1973. Causation. The Journal of Philosophy 70: 556-67.

Lewis, D. 1976. The paradoxes of time travel. American Philosophical Quarterly 13: $145-52$.

Lewis, D. 1986. On the Plurality of Worlds. Oxford: Blackwell.

Lewis, D. 1994. Humean supervenience debugged. Mind 103: 473-90.

Markosian, N. 1993. How fast does time pass? Philosophy and Phenomenological Research 53: 829-44.

Markosian, N. 1994. The 3D/4D controversy and non-present objects. Philosophical Papers 23: 243-9.

Markosian, N. 2004. A defense of presentism. In Oxford Studies in Metaphysics 1, ed. by D. Zimmerman. Oxford: Oxford University Press.

Markosian, N. 2014. Do you know that you are not a brain in a vat? Logos and Episteme 2: 161-81.

Markosian, N. 2020. Sideways music. Analysis 80: 51-9.

McTaggart, J. E. 1908. The unreality of time. Mind 17: 457-73.

Mellor, D. H. 1998. Real Time II. London: Routledge.

Menzel, C. 2018. Actualism. In The Stanford Encyclopedia of Philosophy, ed. by E. Zalta. https://plato.stanford.edu/entries/actualism/

Miller, K. 2004. Enduring special relativity. The Southern Journal of Philosophy 42: 349-70.

Miller, K. 2017. Is some backwards time travel inexplicable? American Philosophical Quarterly 54: 131-41.

Moss, S. 2012. Four-dimensionalist theories of persistence. Australasian Journal of Philosophy 90: 671-86.

Paul, L. A. 2010. Temporal experience. The Journal of Philosophy 107: 333-59.

Plantinga, A. 1974. The Nature of Necessity. Oxford: Oxford University Press.

Price, M. 1977. Identity through time. The Journal of Philosophy 74: 201-17.

Prior, A. 1967. Past, Present and Future. Oxford: Oxford University Press.

Prior, A. and Fine, K. 1977. Worlds, Times and Selves. Amherst: University of Massachusetts Press.

Reichenbach, H. 1956. The Direction of Time. New York: Dover Publications.

Sider, T. 2001. Four-Dimensionalism. Oxford: Oxford University Press. 
Sider, T. 2002. Time travel, coincidences and counterfactuals. Philosophical Studies 110: 115-38.

Sider, T. 2005. Traveling in A- and B- time. The Monist 88: 329-35.

Smart, J. J. C. 1966. The river of time. In Essays in Conceptual Analysis, ed. by A. Flew. New York: St. Martin's Press.

Sullivan, M. 2012. The minimal A-theory. Philosophical Studies 158: 149-74.

Sullivan, M. 2018. Time Biases. Oxford: Oxford University Press.

Thomson, J. J. 1983. Parthood and identity across time. The Journal of Philosophy 80: $201-20$.

Vihvelin, K. 1996. What time travelers cannot do. Philosophical Studies 81: 315-30.

Williams, D. C. 1951. The myth of passage. The Journal of Philosophy 48: $457-72$.

Zimmerman, D. 2008. The privileged present: defending an 'A-Theory' of time. In Contemporary Debates in Metaphysics, ed. by T. Sider, D. Zimmerman, and J. Hawthorne. Oxford: Blackwell. 